\title{
Solidification Behavior and Microstructure Analysis of a Cold Working Die Steel Prepared by Vacuum Arc Melting
}

\author{
Kai Fang ${ }^{1}$, Feng Huang ${ }^{1,2, *}$, Jianxin Zhou ${ }^{2}$, Xinwang $\mathrm{Liu}^{2}$, Qingyan $\mathrm{Xu}^{1}$, Xunpeng Qin ${ }^{1}$ \\ ${ }^{1}$ Hubei Key Laboratory of Advanced Technology of Automobile Parts, Wuhan University of Technology, Wuhan, 430070, China \\ ${ }^{2}$ School of Materials Science and Engineering, Huazhong University of Science and Technology, Wuhan, 430074, China \\ *Corresponding author
}

\begin{abstract}
A new cold working die steel was prepared by vacuum arc melting. Its structure characteristics and micro-hardness were measured and investigated. The results indicate that the ingot is mainly composed of dendrites. The grain size increases gradually from the edge to the center along the horizontal direction. Along the longitudinal direction, the structure distributes axial-symmetrically and its evolution characteristics in the upper part differ from that in the lower part. The grain boundary segregates are eutectics composed of ferrite matrix and Cr carbides. Compared with the original Cr12MoV matrix steel, the solidification structure of the composition modified steel is improved, resulting in the lower hardness.
\end{abstract}

Keywords-vacuum arc melting; cold working die steel; microstructure; solidification behavior

\section{INTRODUCTION}

Due to its good hardenability, high hardness, high wear resistance and low price, $\mathrm{Cr} 12 \mathrm{MoV}$ has become the most widely used cold stamping die steel [1]. However, since the $\mathrm{Cr}$ content is high, a large number of inhomogeneous eutectic carbide networks are always present in its solidification structure, resulting in poor ductility and toughness, which cannot meet the requirements for stamping high strength steel parts. Therefore, it is necessary to study the solidification behaviors to improve its solidification structure [2].

Optimizing alloy composition is one of the most common and effective method to control the solidification behaviors and improve its microstructure. Causing the $\mathrm{C}$ curve to move towards right, Mo could improve the hardenability of the steel and play a solid solution strengthening effect, resulting in increasing the hardness and strength. Furthermore, through increasing the volume fraction of $\mathrm{M}_{7} \mathrm{C}_{3}$ carbide in the steel, Mo could improve its wear resistance [3]. Forming fine and dispersion VC, V could refine the grain in the steel and improve its wear resistance [4]. In this paper, based on the composition of $\mathrm{Cr} 12 \mathrm{MoV}$ matrix steel, Cr content is reduced appropriately to alleviate the carbide segregation at the grain boundaries. Meanwhile, the contents of $\mathrm{Mo}$ and $\mathrm{V}$ are increased to refine the grain and guarantee the requirements of hardness and wear resistance. Using non-consumable vacuum arc smelting technology, the new alloy with this modified composition was melted and solidified. The structure characteristics were measured and its solidification behaviors during this arc melting process were analyzed.

\section{EXPERIMENTAL METHODS}

In this study, the Cr12MoV matrix steel, pig iron, Mo iron and $\mathrm{V}$ iron were used as raw material, and according to the composition listed in Table.1, $100 \mathrm{~g}$ alloy was weighted by electronic scales. A non-consumable vacuum arc melting furnace was used to melt this alloy. For avoiding oxidation, the chamber was evacuated to $3 \times 10^{-3} \mathrm{~Pa}$ and then filled with argon to $0.05 \mathrm{Mpa}$, and this process was repeated for 3 times to eliminate the residual oxygen completely. In order to stabilize the arc and control the melting rate, the arc voltage was fixed at $60 \mathrm{~V}$ and the current changed according to the rule shown in Fig.1. In addition, in order to obtain a uniform composition in the ingot, 5 cycles of "melting-cooling-turning” were conducted to obtain the final ingot.

TABLE I.

COMPOSITION OF THE STEELS (WT\%)

\begin{tabular}{cccccccccccc}
\hline Steels & $\mathbf{C}$ & $\mathbf{S i}$ & $\mathbf{V}$ & $\mathbf{C r}$ & $\mathbf{M n}$ & $\mathbf{N i}$ & $\mathbf{M o}$ & $\mathbf{C u}$ & $\mathbf{P}$ & $\mathbf{S}$ & $\mathbf{F e}$ \\
\hline New steel & 1.62 & 0.28 & 0.85 & 11.65 & 0.25 & 0.15 & 0.50 & 0.20 & 0.03 & 0.03 & The rest \\
Matrix steel & 1.62 & 0.27 & 0.07 & 12.00 & 0.27 & 0.20 & 0.04 & 0.18 & 0.03 & 0.03 & The rest \\
\hline
\end{tabular}

The obtained button ingot with a diameter of about $45 \mathrm{~mm}$ and a center thickness of about $10 \mathrm{~mm}$ is shown in Figure 2(a). For detecting its structure characteristics, the ingot was cut along its longitudinal direction into two parts, as shown in
Figure 2(b). After etched with 4\% nitric acid alcohol solution, the metallographic structure of the sample was observed by optical microscope (OM). And in order to analyze the structure distribution and its evolution characteristics along 
the longitudinal (thickness) and horizontal (diameter) directions, the metallographic structures at 7 different positions were detected, as shown in Figure 2(b). Wherein, the convex surface corresponds to the bottom surface which is contacted with the cold crucible wall and the concave surface corresponds to the top free surface. The microstructure was detected by scanning electron microscope (SEM) equipped with energy dispersive spectroscopy (EDS). The distribution characteristics of the main alloying elements were analyzed by electron probe micro-analyzer (EPMA). The phases present in the solidified ingot were identified by $\mathrm{x}$-ray diffraction (XRD). The micro-hardness was tested on a HV-1000A hardness tester, during the test, the load was fixed at $500 \mathrm{~g}$ and the holding time was $10 \mathrm{~s} .15$ points were measured for the same position and the average value was calculated after the maximum and minimum values were removed.

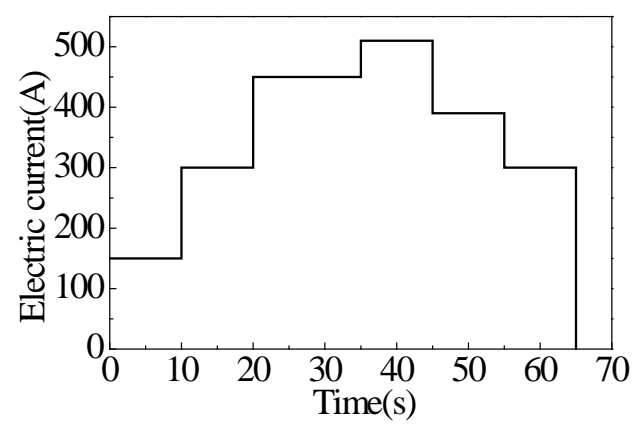

\section{FIGURE I. CURRENT VARIATION DURING SMELTING}

\section{RESULTS AND DISCUSSIONS}

\section{A. Metallographic Structures of the Ingot}

The metallographic structures detected at different positions (1,2 and 5) of the ingot along its horizontal direction are shown in Figure 3. It is clear that, both the metallographic structures at different positions are mainly composed of dendrites, and the secondary dendrites grow almost perpendicular to the first dendrites. In addition, resulting from the segregation during the solidification process, a certain amounts of black and gray segregations are present at the grain boundaries.

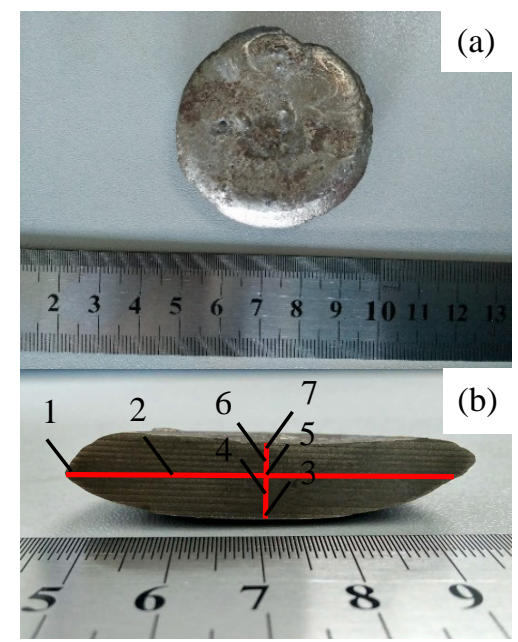

\section{FIGURE II. THE INGOT AND ITS MICROSTRUCTURE ANALYZING POSITIONS (A) THE BUTTON INGOT (B) MICROSTRUCTURE ANALYZING POSITIONS}

Comparing the three metallographic structures shown in Figure 3, it is can be found that, at the edge (position 1), resulting from the fast cooling, the arm spacing of the first dendrite is small and a certain amounts of fine equiaxed grains are formed. In addition, as the first dendrite always grows parallel to the heat flow direction [5], then resulting from the outline and cooling conditions at the edge, the first dendrite axis at position 1 is nearly $45^{\circ}$ inclined upwards. As position 2 is away from the radial edge and the thickness at this position is increased, then the cooling rate is reduced, resulting in the coarsening of the crystals. Furthermore, as the heat dissipation rate in the longitudinal direction surpass that in the horizontal, the inclination degree of the crystal axis increases towards the longitudinal direction. In the center (position 5), due to the heat dissipation conditions in the left and right are almost the same, the first dendrites distribute almost symmetrically. Meanwhile, as the thickness of position 2 and 5 are similar, the heat dissipation rate is almost the same and then the grain size in these two positions is nearly equal to each other. In addition, as Figure 3 showing, due to the higher cooling rate, the melt solidifies fast and then limited by the element migration kinetics, the segregation degree at position 1 is slightly less than that at position 2 and 5 . The morphology and phase composition of the segregates at the grain boundaries will be discussed latter.
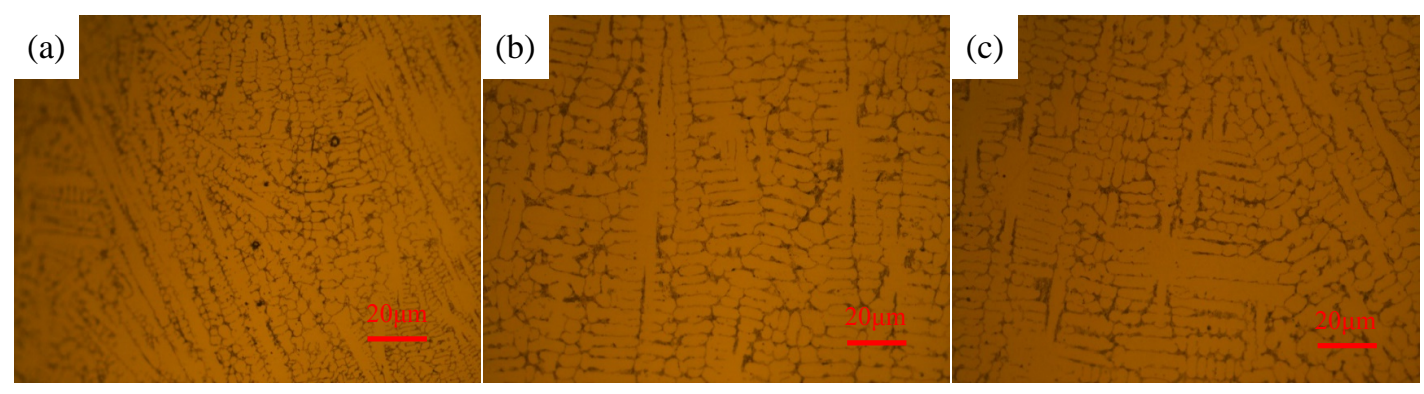

FIGURE III.

METALLOGRAPHIC STRUCTURES AT DIFFERENT POSITIONS ALONG THE HORIZONTAL DIRECTION OF THE INGOT (A) POSITION 1 (B) POSITION 2 (C) POSITION 5 
The statistical results of the average grain size levels at position 1, 2 and 5 are shown in Figure 4. As the same shown in Figure 3, the structure in the edge area is the finest and its average grain size level reaches 8.43 . At the $1 / 4$ width and center in horizontal direction, the average grain size levels are similar, which is 7.65 and 7.74 respectively.

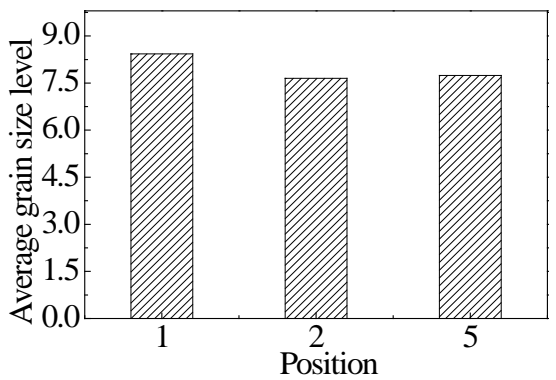

FIGURE IV

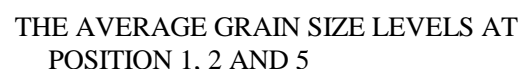

Figure 5 shows the metallographic structures detected at different positions $(3,4$ and 5$)$ in the lower part of the ingot along its longitudinal direction. At position 3 , which is contacted with the cold crucible, resulting from the strong cooling from the crucible wall, a large number of crystal nuclear were formed and the solidification rate was high, resulting in the small arm spacing of the first dendrite and presence of fine equiaxed grains. At position 4 , as the heat dissipation condition is worsened, the super-cooling degree is then reduced and thus the number of crystal nuclear is decreased, resulting in the coarsening of the dendrites and elimination of the fine equiaxed grains. As the metallographic structure characteristic in the center of the ingot (position 5) has been described above, so it is not repeated hear. In addition, since positon 3, 4 and 5 are located on the axis of the ingot, the heat dissipation conditions in the left and right are almost the same, resulting in the structures distribute almost symmetrically. As the same discussed above, resulting from the slow cooling rate and relatively sufficient element diffusion, the grain boundary segregation at position 4 and 5 are slightly more serious than that at position 3 .

The average grain size levels of the solidification structures at positon 3, 4 and 5 are shown in Figure 6. As the figure showing, the average grain size levels at these three positions are $7.90,7.70$ and 7.74 respectively, indicating that the grain size at position 3 is slightly smaller than that at position 4 and 5.

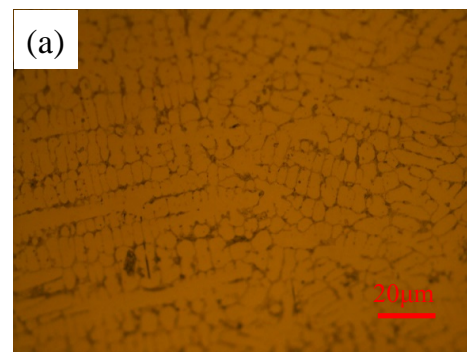

(b)
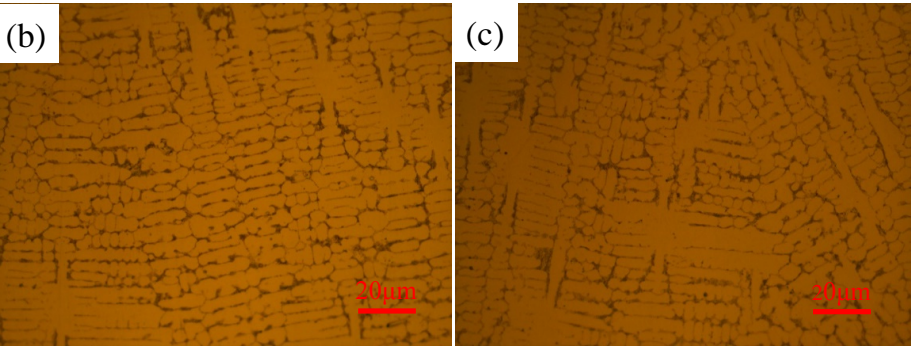

FIGURE V.

METALLOGRAPHIC STRUCTURES AT DIFFERENT POSITIONS ALONG THE LONGITUDINAL DIRECTION OF LOWER PART OF THE INGOT (A) POSITION 3 (B) POSITION 4 (C) POSITION 5

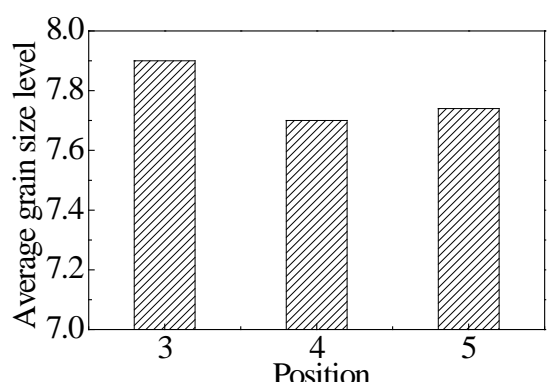

FIGURE VI.

THE AVERAGE GRAIN SIZE LEVELS AT POSITION 3, 4 AND 5

Figure 7 shows the metallographic structures measured at different positions in the upper part of the ingot along its longitudinal direction. Differing from the lower part, the grains above the radial central axis grow irregularly. In the middle of the upper part (positon 6), the first dendrites disappear gradually and the number of equiaxed grains and columnar crystals increase. At the top free surface (position 7), resulting from the fast cooling through surface radiation, the nucleation rate is high and a layer with very fine equiaxed grains is formed on the surface, as shown in the upper part of Figure 7(b).
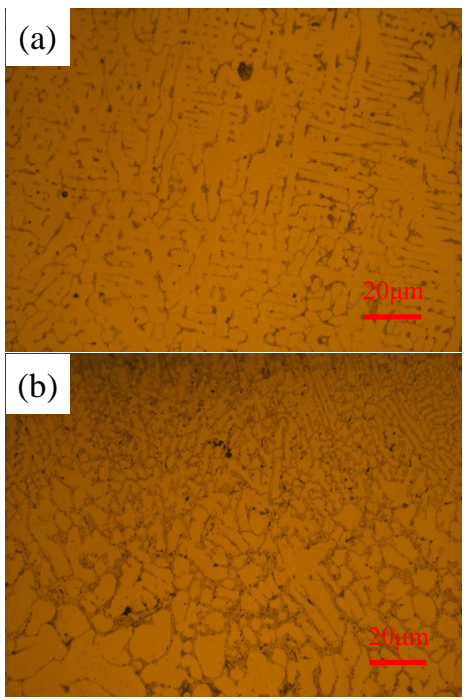

FIGURE VII. METALLOGRAPHIC STRUCTURES AT DIFFERENT POSITIONS ALONG THE LONGITUDINAL DIRECTION OF UPPER PART OF THE INGOT (A) POSITION 6 (B) POSITION 7 
During this arc melting process, as the cold crucible is cooled by flowing water continuously, then the chilling effect of the melt from the bottom crucible is stronger than that from the free surface radiation, resulting in the upper part solidifies slightly slower than the lower part. Based on this, the grain boundary segregation in the upper part is slightly more serious than that in the lower part, especially in the final solidified area, and shrinkage porosity defect is appeared, as shown in Figure 7.

The average grain size levels of the solidification structures at positon 5, 6 and 7 are shown in Figure 8. Agree with that discussed above, due to the strong cooling trough surface radiation, the gain size at position 7 is the smallest, which average grain size level reaches 9.54. As the area near position 6 solidifies finally, the grain size is the largest, which average grain size level is only 6.49 . The average grain size level at position 5 ranks in the middle, which is 7.74 .

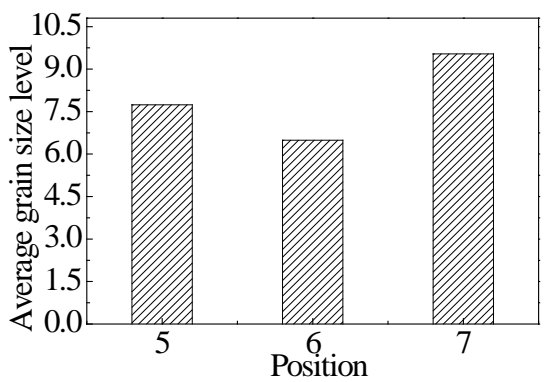

\section{FIGURE VIII. THE AVERAGE GRAIN SIZE LEVELS AT POSITION 5, 6 AND 7}

\section{B. Microstructures of the Ingot}

For characterizing the structure morphologies such as the grain boundary segregates more clearly, SEM measurement was introduced. And for evaluating the effectiveness of the composition modification, the microstructures of the Cr12MoV matrix steel arc-melted under the same parameters were also detected. The results are shown in Figure 9. As can be seen from the figure, after the composition is modified, there is still skeletal-like and reticular distributed segregates precipitated at grain boundaries. However, as compared with the original matrix steel, the grain is refined and the amount of grain boundary segregates is reduced in a certain degree. Furthermore, the segregates networks are broken in some areas in this composition modified alloy.

The segregates precipitated at the grain boundaries are further enlarged, and their morphologies are shown in Figure 10. As the figure showing, the grain boundary precipitates mainly consist of two phases, colored by white and gray respectively. According to their commutative growth characteristics, this grain boundary segregates are preliminarily judged as some eutectics.

The composition of the matrix and grain boundary precipitates are analyzed by EDS, and the results are shown in Figure 11, in which spectrum 1 and 2 correspond to matrix and grain boundary precipitates respectively. As the figure showing, the grain boundary precipitates are mainly composed of $\mathrm{C}, \mathrm{Cr}$ and $\mathrm{Fe}$, indicating the eutectics are composed of $\mathrm{Fe}$ and $\mathrm{Cr}$ carbides. In addition, Mo and $\mathrm{V}$ segregate into these eutectics. The matrix is mainly composed of Fe, and a small amount of other alloying elements such as $\mathrm{Cr}, \mathrm{Mn}, \mathrm{Si}$ and V dissolve in the matrix. Comparing these two spectrums, the content of $\mathrm{Si}$ in the matrix is almost the same as that in the grain boundary precipitates, indicating that it is not a carbide forming element in this steel. Mn is mainly distributed in the matrix, and the dissolve of $\mathrm{Mn}$ and $\mathrm{Si}$ in the matrix can strengthen the matrix [6]. Furthermore, as can be seen from Spectrum 2, the $C$ content in the matrix reaches $0.49 \%$, which surpass its solid solubility in ferrite at room temperature (generally less than $0.008 \%$ ), indicating there must be some retained austenite or martensitic in the matrix.
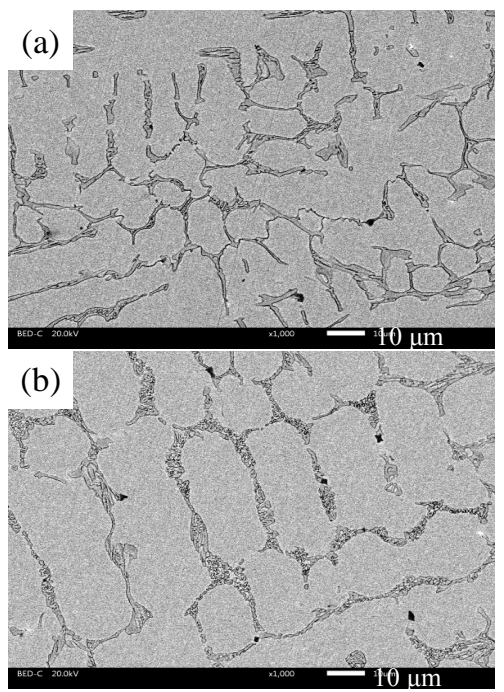

FIGURE IX. SEM IMAGES OF THE COMPOSITION MODIFIED STEEL (A) AND THE ORIGINAL MATRIX STEEL (B)

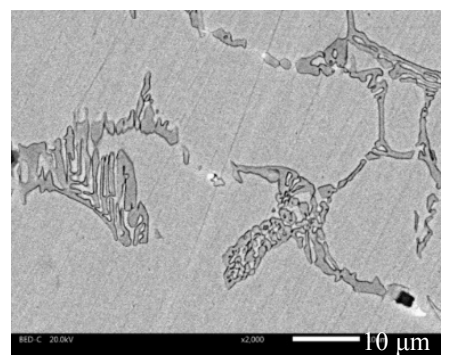

FIGURE X. MORPHOLOGY OF EUTECTIC STRUCTURE

For further identifying the alloying elements contained in each phase and their distributions, EPMA measurement was employed. The testing results are shown in Figure 12. It is clear that, $\mathrm{Cr}, \mathrm{V}$ and Mo are mainly segregated at the grain boundary. As some point-like high enrichment region of Mo and $\mathrm{V}$ are present at the grain boundary, it is speculated that the Mo and V carbides may be formed, especially for Mo. In addition, as can be seen from the Cr distribution map, although the grain boundary eutectics are still reticular, the networks have been broken in some areas. The same as that detected by EDS, Fe is mainly distributed in the matrix and Si distributes uniformly. 


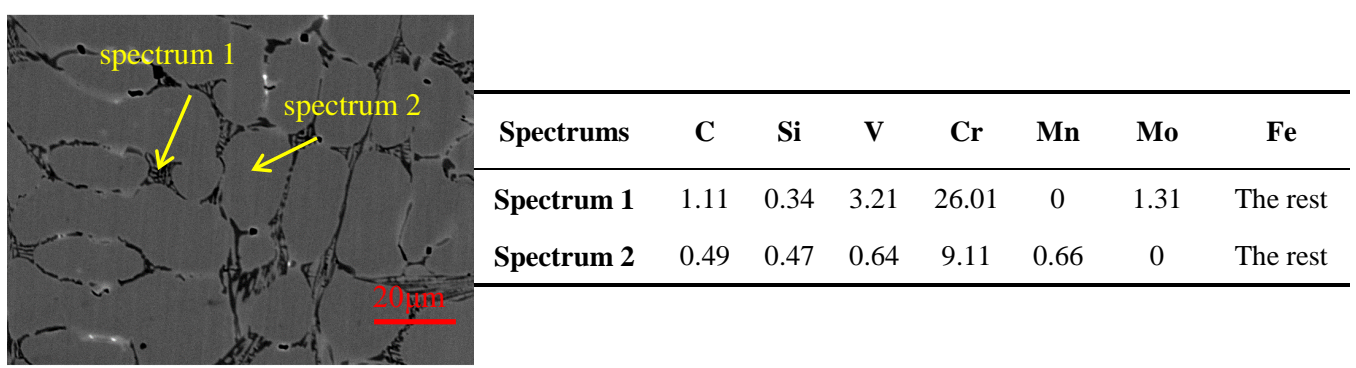

FIGURE XI. EDS ANALYSIS OF THE MATRIX AND GRAIN BOUNDARY PRECIPITATES

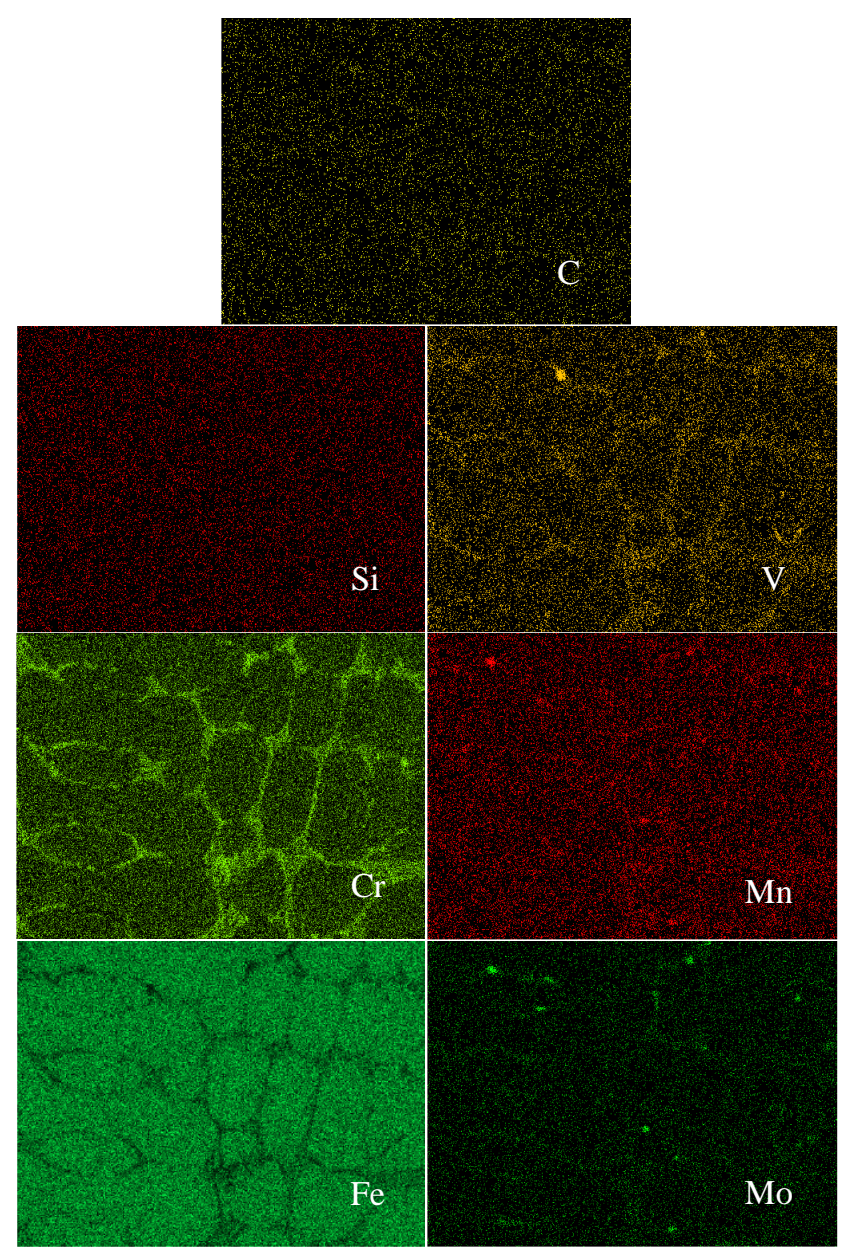

FIGURE XII.

ELEMENTS DISTRIBUTIONS MEASURED BY EPMA

The phase analyzing result detected by XRD is shown in Figure 13. It shows that the solidification structure of this composition modified steel prepared by vacuum arc melting mainly contains $(\mathrm{Fe}, \mathrm{Cr})_{7} \mathrm{C}_{3}$, ferrite phase and retained austenite phases. According to the above analysis and the corresponding intensity of diffraction peaks shown in Figure 13 , the matrix should be ferrite and a small amount of retained austenite is included. The gray phase at the grain boundary is $(\mathrm{Fe}, \mathrm{Cr})_{7} \mathrm{C}_{3}$. Since $\mathrm{Cr} 12 \mathrm{MoV}$ belongs to a high chromium and carbon steel, the elements such as $\mathrm{C}$ and $\mathrm{Cr}$ will segregate and be enriched at the solid-liquid interface during solidification, causing composition supercooling, especially in the coarse first dendrite and secondary dendrite arms. When the molten melt cooled to its eutectic temperature, the eutectic reaction will be activated, and then carbide and austenite will alternately grow to form eutectics, which are always reticular and continuously distributed at grain boundaries [7]. Because the hardness of $(\mathrm{Fe}, \mathrm{Cr})_{7} \mathrm{C}_{3}$ is very high, then the high wear resistance and hardness of $\mathrm{Cr} 12 \mathrm{MoV}$ should be attributed to the eutectic structures distributed at the grain boundaries $[8,9]$. Unfortunately, it is this hard carbide which is often exhibited as the source of cracks and then reduces the ductility and toughness of this cold working die steel greatly.

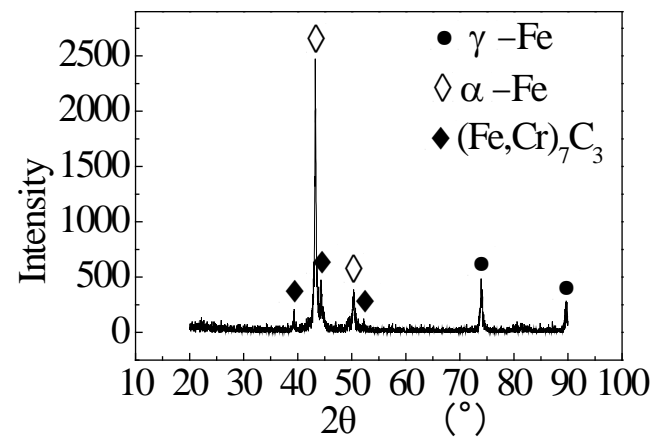

FIGURE XIII.

\section{XRD PATTERN OF THE COMPOSITION} MODIFIED STEEL

\section{Microhardness of the Ingot}

The micro-hardness of this composition modified steel and the $\mathrm{Cr} 12 \mathrm{MoV}$ matrix steel were tested. As mentioned in the previous section, the structure of the ingot prepared by vacuum arc melting is inhomogeneous, resulting in the mechanical properties are different at different locations. Then for reducing or eliminating the effect of locations and improving the reliability in comparing the mechanical properties of this two steels, both the tested samples are cut from the same area (near position 5) of each ingot.

As shown in Table 2, the results show that the micro-hardness of this composition modified steel is slightly lower than that of the original matrix steel. As discussed above, the hardness and wear resistance mainly depend on the eutectic carbide proportion and its distribution in the structure, and then since the carbide segregation is reduced and the grain boundary segregates network is broken in some areas in this composition modified steel, the hardness is reduced slightly. 
It should be pointed that the required hardness could be achieved by the subsequent heat treatment.

TABLE II.

\begin{tabular}{ccc}
\hline Hardness & Matrix steel & New steel \\
\hline HRC & 41.0 & 39.8 \\
HV & 393.1 & 379.2 \\
\hline
\end{tabular}

D. Summary

In this paper, the solidification structure and micro-hardness of a composition modified cold working die steel were measured and its solidification behaviors were analyzed. The following conclusions can be made:

1) The ingot is mainly composed of dendrites. Along the horizontal direction, the grain size increases from the edge to the center. Along the longitudinal direction, the metallographic structure distributes axial-symmetrically and the structure evolution characteristics in the upper part differ from that in the lower part. In the upper part, the amount of dendrites decreases while that of columnar grains and equiaxed grains increase, and the shrinkage porosity defects are emerged.

2) The grain boundary segregates are eutectics composed of ferrite matrix and $\mathrm{Cr}$ carbides, enriched with a certain amount of Mo, $\mathrm{V}$ and their carbides.

3) Compared with the $\mathrm{Cr} 12 \mathrm{MoV}$ matrix steel, the grain is refined, the amount of grain boundary segregates is reduced and the segregates network is interrupted in some area in this composition modified steel.

4) Resulting from the improvement of the solidification structure, the micro-hardness of this composition modified steel is slightly lower than that of the original $\mathrm{Cr} 12 \mathrm{MoV}$ matrix steel.

\section{ACKNOWLEDGEMENT}

This project was supported by State Key Laboratory of Material Processing and Die \& Mould Technology, Huazhong University of Science and Technology (P2016-06). The authors are thankful to Ruirun Chen and Yong Yang in Harbin Institute of Technology for supporting the sample preparation.

\section{REFERENCES}

[1] De-jun Kong, Chun-yang Xie. "Effect of laser quenching on fatigue properties and fracture morphologies of boronized layer on Cr12MoV steel,” International Journal of Fatigue, vol. 80 , pp. 391-396, 2015.

[2] Sander J, Hufenbach J, Giebeler L. "Microstructure, mechanical behavior, and wear properties of FeCrMoVC steel prepared by selective laser melting and casting,” Scripta Materialia, vol. 12, pp. 41-44, 2017.

[3] Seungmun Jung, Yong Hee Jo, Changwoo Jeon. "Effects of Mn and Mo addition on high-temperature tensile properties in high-Ni-containing austenitic cast steels used for turbo-charger application,” Materials Science and Engineering: A, vol. 682, pp. 147-155, 2017.
[4] Reyes-Calderón F, Mejía I, Boulaajaj A. "Effect of microalloying elements ( $\mathrm{Nb}, \mathrm{V}$ and $\mathrm{Ti})$ on the hot flow behavior of high-Mn austenitic twinning induced plasticity (TWIP) steel," Materials Science and Engineering: A, vol. 560: pp. 552-560, 2013.

[5] Wieczerzak K, Bala P, Stepien M. "Formation of eutectic carbides in Fe-Cr-Mo-C alloy during non-equilibrium crystallization,” Materials \& Design, vol. 94, pp. 61-68, 2016.

[6] Kookhyun Jeong, Jae-Eun Jin, Yeon-Seung Jung. “The effects of Si on the mechanical twinning and strain hardening of Fe-18Mn-0.6C twinning-induced plasticity steel," Acta Materialia, vol. 61, pp. 3399-3410, 2013.

[7] Wu X Q, Jing H M, Zheng Y G. "The eutectic carbides and creep rupture strength of $25 \mathrm{Cr} 20 \mathrm{Ni}$ heat-resistant steel tubes centrifugally cast with different solidification conditions,” Materials Science and Engineering: A, vol. 293, pp. 252-260, 2000.

[8] Wieczerzak K, Bala P, Dziurka R. "The effect of temperature on the evolution of eutectic carbides and M7C3 $\rightarrow$ M23C6 carbides reaction in the rapidly solidified Fe-Cr-C alloy,” Journal of Alloys and Compounds, vol. 698, pp. 673-684, 2017. unpublished.

[9] Coronado J J, "Effect of (Fe,Cr)7C3 carbide orientation on abrasion wear resistance and fracture toughness,” Wear, vol. 270, pp. 287-293, 2011. 